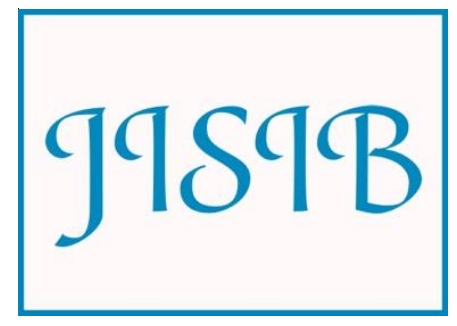

Available for free online at https://ojs.hh.se/

Journal of Intelligence Studies in Business 3 (2012) 5-11

\title{
Benchmarking Competitive Intelligence Activity
}

\author{
Helen N. Rothberg ${ }^{1}$ and G. Scott Erickson ${ }^{2}$ \\ ${ }^{1}$ Marist College, Poughkeepsie, USA \\ hnrothberg@aol.com \\ ${ }^{2}$ Ithaca College, Ithaca, USA \\ gerickson@ithaca.edu
}

\begin{abstract}
This paper reports on results drawn from a comprehensive database formed from public financial reports and a proprietary benchmarking survey conducted by a major competitive intelligence consulting firm. Our overall aim is to identify different circumstances in which knowledge development and knowledge protection have greater or lesser importance. Very little work has been done on a industry-wide (or wider) basis concerning intellectual capital and/or competitive intelligence activities in firms and how that may vary according to circumstances. The wider study and database are designed to better address such questions.
\end{abstract}

In this study, we look at one piece of this overall research program, specifically how competitive intelligence activity varies in distinctive environments. Based on these results, as practitioners better understand their environments, they can make better decisions on the level and aggressiveness of their own CI operations as well as on protection and counterintelligence efforts. The results will also begin to move scholarly work in the field into these new areas of macro studies and strategic choices.

KEYWORDS: Competitive Intelligence, Knowledge Management, Competitive Capital

\section{Background}

Competitive intelligence (CI) is a field drawing increasing interest from scholars, both on its own merits and as an important piece of a firm's knowledge assets. Much of the standard knowledge management (KM) and intellectual capital (IC) theory applies directly to $\mathrm{CI}$ as it focuses on a specific type of knowledge, that concerning competitors, But CI also has its own theory and practice, going beyond the standard KM/IC concepts, most notably within its specialized gathering and processing techniques.
In past work, the connection between CI and $\mathrm{KM} / \mathrm{IC}$ has been explored, particularly how competitive knowledge is an additional valuable intangible asset, beyond the standard theoretical constructs of human, structural, and relational capital (Bontis 1999, Edvinsson \& Sullivan 1996). In addition, however, $\mathrm{CI}$ adds to the discussion by emphasizing the importance of data and information as valuable precursors to knowledge. CI operations can often obtain pieces of data and information that can be turned into knowledge proper with appropriate analytical processing- 
what we've termed competitive capital in another context (Rothberg \& Erickson 2002). Further, CI starkly demonstrates the need for security as the knowledge valuable to one party is often likely to be similarly valuable to its competitor(s) (Rothberg \& Erickson 2005).

As such, CI is appropriate as a topic in the study of knowledge assets, providing a different perspective and deeper insights beyond the standard fare of the discipline. By better understanding how CI works and its best practices, we are able to add also to our knowledge concerning $\mathrm{KM}$ in general. This alternative point-of-view has the potential to add deep insights as we move beyond the standard ways of assessing and managing organizational knowledge.

Competitive intelligence, in much the way KM/IC did, grew first out of practice (Gilad \& Herring 1996; Fuld 1994). While there is something of a scholarly trail before CI was recognized in the late eighties and early nineties, the discipline as we know it really grew out of observing what was happening in industry. Competitor analysis at the cursory level was giving way to more formal, complete, and innovative methods of uncovering information concerning one's competitors and turning that, through appropriate analysis, into knowledge and actionable intelligence.

The methods are now well-enough developed to merit textbook-like treatment (Fleisher \& Bensoussan 2002). Basically, CI practice includes a scanning function (public information and other sources, including heavy use of the internet), human intelligence, and more active gathering techniques (McGonagle \& Vella 2002; Prescott \& Miller 2001). From the resulting information and knowledge, CI practitioners seek to glean competitive strategies and actions, anticipating and countering those moves threatening their firms (Gilad 2003; Bernhardt 1993). Competencies range from pure library functions to highly competent, seasoned analytical teams (Wright, Picton \& Callow 2002; Rouach \& Santi 2001).

The basic structure of most CI operations is a mix of data, information, and knowledge-gathering processes with analytical tools and techniques. As just noted, sometimes the information assetgathering is from secondary sources. In other, usually more sophisticated operations, the sources can be primary, human intelligence or from purpose-driven active gathering. Tools for analyzing the information assets range from environmental scanning to war games. Other differences in operations can include reporting topics (project-driven or ongoing operations), size and make-up (internal or external) of the CI team, reporting level (C-suite, dispersed), and budget. As we'll discuss, our overall research program is aimed at understanding how and why these differences exist and whether certain CI operations are better for certain circumstances.

In a wider context, in past work, we've looked at how firms vary their knowledge strategies (both development, as with KM and IC and protection/competitive analysis, as with $\mathrm{CI}$ ) according to circumstances. Essentially there are differences in the degree to which firms invest in identifying and growing knowledge assets, and there are also differences in the threat posed by competitors in appropriating these assets through CI. The firms themselves may also employ CI to a greater or lesser degree. Much of our scholarship has been focused on the how and why. If you can identify circumstances, industries, and firms that aggressively develop knowledge (or not) and that aggressively pursue competitive intelligence (or not), then we begin to get a better sense of the strategic implications for each.

In this paper, we'll report on competitive intelligence practice in two very different scenarios. In one, situation, knowledge is extremely important for competitiveness, so both the creating firm and its competitors are quite interested in the proprietary knowledge and in using it for competitive advantage. We'll refer to this as a high-value knowledge scenario. Alternatively, we also look at a situation, wherein knowledge is apparently not particularly useful to the originating firm nor to its competitors. This will be the lowvalue knowledge situation. We'll elaborate on each situation a bit more in the discussion and then look specifically at how firms in each scenario conduct their CI operations, if they exist at all. From this analysis, we should be able to help guide CI investment and practice for firms facing different competitive environments.

\section{Strategic Protection Factor (SPF) Framework and the Fuld \& Company Database}

We have previously developed and analyzed a framework describing four different scenarios concerning knowledge development and knowledge protection, two aspects of KM that are seemingly in some conflict with one another (Erickson \& Rothberg 2012, Rothberg \& Erickson 2005). At its simplest level, the more knowledge is developed and spread throughout an organization and its network partners, the more vulnerable it is to competitor capture. The natural conclusion is that knowledge is valuable to both its originator and to potential competitors. 
Our research, however, indicates that this view is too simplistic. While valuable knowledge is something firms want to leverage through distribution, not all firms possess valuable knowledge and not all valuable knowledge is relevant or transferable to competitors. There are a number of potential reasons for this state of affairs, too lengthy to go into here in any detail, but most are familiar to those in the KM field (tacitness, complexity, specificity) or those with a background in strategy (life cycle, value chain, etc.). These conceptual ideas can be backed up by in-depth quantitative support, demonstrating knowledge that is valuable in an industry (or not) and of apparent interest to competitors (or not) (Erickson \& Rothberg 2012).

These two variables yield four potential states of affairs, as with any two-by-two matrix, that we have characterized as the Strategic Protection Factor (SPF) framework. In short, these break down as:

- $\quad$ SPF 45: high levels of KM, high levels of CI

- SPF 30: low levels of KM, high levels of $\mathrm{CI}$

- SPF 15: high levels of KM, low levels of CI

- SPF 5: low levels of KM, low levels of CI

For this analysis, and to gain readily comparable results, we chose to look at the two extremes (SPF 45 and SPF 5) in this paper, the situations where the differences in practice would be most noticeable. When knowledge is valuable to all, as in high/high SPF 45 or when knowledge has questionable value to all, as in low/low SPF 5, we should find the clearest distinctions in practives Hence, this paper examines industries in which knowledge is extremely valuable, based on the level of intangible assets (intellectual capital) required to compete as well as industries in which knowledge is of little value, at least formally, with low levels of intangible assets apparent. The first group of industries in our analysis also includes high levels of competitive intelligence activity (self-reports on capabilities combined with number of participating firms), suggesting the knowledge is also important to competitors. Again, we'll refer to this as highvalue knowledge. The second group includes low levels of CI and limited participation, demonstrating little to no competitor interest in acquiring knowledge. This is low-value knowledge.

The data used in this analysis are from a large database constructed to examine the entire knowledge development vs. knowledge protection issue in greater detail. The full database include five years of financial information from 2,000 or so firms (2006-2010) as well as five years of data from a proprietary Fuld \& Company benchmarking study on competitive intelligence capabilities.

From this database, for the larger project, we constructed a breakdown of industries according to the value of intangible assets (calculated by a variation on Tobin's q, market capitalization over physical asset value) and, as noted, the prevalence of CI activity in the industry. Tobin's q has a long history of use in measuring intangible assets (Tobin \& Brainard 1977) and remains useful up to the present day (Villalonga 2004). A wide variety of metrics for intellectual capital exist, but if one wants to measure across a number of firms, the objective and readily available financial data found in Tobin's q make it the preferred tool (Tan, Plowman \& Hancock 2007, Sveiby 2010). Indeed, it is the only practical way to try to determine IC levels across the number of firms included in our database.

The Fuld \& Company data come from a worldwide competitive intelligence benchmarking study conducted over several years. The available data, at the time we were given access, included almost 1000 respondents providing self-report responses to a variety of questions concerning CI practice in their firms. The result is an unparalleled in-depth look into CI operations, on a number of levels. We used the data to construct industry-by-industry snapshots of the number of firms and level of sophistication of competitive intelligence activities. Of note is that the Fuld \& Company benchmarking results matched up well, on this industry basis, with an earlier study we conducted using Society of Competitive Intelligence Professional (SCIP) membership database.

As noted earlier, represented here are the industries that were the highest of the high in terms of both variables (intangibles value according to the Tobin's q variation and CI activity) and those in the lowest quadrant of the framework, with low intangibles value and low, but nonzero, CI activity.

\section{Methodology and Results}

From within the wider study, we identified eight industries in the highest part of the highest knowledge sector with enough observations (firms and years) to justify a closer look. All of these industries had a market capitalization to assets ratio above 1.4 combined with, multiple firms utilizing aggressive CI. At the other extreme, we identified eleven industries in the lowest knowledge sector with appropriate observations. Each of these industries had a market capitalization to assets ratio 
below 1.0 and had minimal CI participation by firms.

The highest sector, for example, included SIC 2834, Pharmaceutical Preparations, and SIC 7372, Prepackaged Software. Pharmaceuticals shows a cap/assets ratio of 1.94 and twenty-seven different firms that report some level of CI activity (many at very high levels and with significant resources devoted to the initiatives). Software has a ratio of 2.14 and thirty identifiable firms with CI operations. Essentially, we have firms here with extensive intangible assets/IC (firms valued at about twice as much as their physical assets would justify) and extensive industry CI activity.

Alternatively, the lowest sector includes industries such as SIC 351, Engines and Turbines, and 4931, Electric Services, with cap/asset ratios of 0.71 and 0.43 , respectively. Each of these industries includes only a single firm with any CI activity, and even that is at a relatively low level. These are very different circumstances and very different approaches to knowledge. The firms here are worth less than their tangible assets would imply (no intangibles evident) and very little CI activity is taking place.

From these categories and the industries/firms identified in each, we were able to take a closer look at the Fuld \& Company dataset. From within the highest sector, we were able to select 96 observations from different respondents to the benchmarking study. Similarly, we were able to draw 11 observations from the lower sector. While more equal samples would be preferable, remember that the nature of the data is that the one sector has lots of CI activity while the other has little. So, almost by definition, we're going to see fewer participants in the lower sector. Even so, the results provide some interesting results, with respondents answering a number of questions concerning their CI operations, including time in place, budget, processes used, types of research employed, analysis techniques, and perceived value to their organizations. These topics are organized in the Table 1, using the SPF references noted earlier. Significance tests are not included due to the small and unbalanced samples, as well as the exploratory nature of this particular application.

Table 1

Competitive Intelligence Characteristics

\begin{tabular}{|l|l|l|l|}
\hline Characteristic & Responses & $\begin{array}{l}\text { SPF 45 NE } \\
(\mathrm{n}=96)\end{array}$ & $\begin{array}{l}\text { SPF 5 } \\
(\mathrm{n}=11)\end{array}$ \\
\hline Time & $>4$ years & 0.33 & 0.00 \\
& $2-4$ years & 0.11 & 0.20 \\
& $1-2$ years & 0.15 & 0.00 \\
& $<$ year & .040 & 0.80 \\
\hline Budget & \$2M & 0.09 & 0.11 \\
& $\$ 1-2 \mathrm{M}$ & 0.05 & 0.11 \\
& \$500K-1M & 0.07 & 0.00 \\
& $\$ 250-500 \mathrm{~K}$ & 0.15 & 0.33 \\
& $\$ 100-250 \mathrm{~K}$ & 0.20 & 0.22 \\
& $<\$ 100 \mathrm{~K}$ & 0.44 & 0.22 \\
\hline Processes & Top-down requests & 0.33 & 0.45 \\
& Intro to Key Intelligence Topics (KIT) & 0.33 & 0.36 \\
& Wider use of KIT's & 0.24 & 0.18 \\
& Embedded in decision-making & 0.10 & 0.00 \\
\hline Secondary Research & Primarily web & 0.15 & 0.00 \\
& Add other external sources & 0.23 & 0.55 \\
& Tap into internal sources & 0.36 & 0.36 \\
& Integrated internal and external & 0.26 & 0.09 \\
\hline Primary Research & None & 0.23 & 0.45 \\
& Recognize value, not timely & 0.25 & 0.36 \\
& Use friendly human network & 0.30 & 0.18 \\
& Integrated internal and external & 0.22 & 0.00 \\
\hline Analysis & None & 0.19 & 0.00 \\
& Occasional basic & 0.37 & 0.45 \\
& Use more analytical tools & 0.32 & 0.45 \\
& Use advanced analytical tools & 0.11 & 0.09 \\
\hline Value Perception & Limited or none & 0.10 & 0.18 \\
& Recognized as necessary & 0.44 & 0.64 \\
& Formal justification and evaluation & 0.37 & 0.18 \\
& Conviction important to decision-making & 0.10 & 0.00 \\
\hline
\end{tabular}




\section{Discussion}

As is clear in the table, we have focused this discussion on how $\mathrm{CI}$ operations in these two different circumstances are distinct in experience, budget, techniques employed and perceived value to the organization.

In the high-value knowledge industries, the CI operations are decidedly more mature. The majority of respondents report functions more than a year old and $44 \%$ have been in place for more than two years. This contrasts with the industries with less knowledge emphasis showing fully $80 \%$ of firms with CI operations less than a year old. While CI capabilities are an evolving competency, when knowledge is viewed as important, firms appear to have started earlier and so to have been in place for a longer period of time.

This maturity does not necessarily translate to budgets, however. The high-value knowledge group does not show significantly higher budgets than the low-value group. The absolute numbers are higher, in terms of firms with budgets in the \$1 million plus category, but in terms of percentages, there are not distinct differences. This state could reflect several things. Initially, it doesn't take much to punch up the percentages in the smaller lowvalue knowledge group, where a single firm in both the $>\$ 2$ million and \$1-2 million categories pushes the percentages into double figures. Secondly, even if knowledge hasn't been valued and firms are late to the game, they may still choose to enter in a big way once they make the decision to pursue competitive intelligence. And, finally, we are dealing with sizable budgets throughout these responses, and a very credible, ongoing CI operation in a high-value industry can be conducted at the lower but still considerable budget levels. Indeed, the difference between a seasoned CI operations that knows its budgetary requirements and a startup operations looking to make a big splash with a big budget is something one does see in industry (and that we have had reported to us in related depth interviews). So time in place and some of the other variables we'll be discussing have not necessarily resulted in higher budgets for CI.

Beyond budgets, another sign of CI maturity is decentralization of the function, a move to a structure where the CI manager(s) have more independence. In such situations, not only do directives come from top management but the CI operation(s) have some freedom to pursue and analyze knowledge on a more persistent, independent basis. In particular, they may be more completely incorporated into decision-making at lower levels, providing the ongoing insights that improve more decentralized management. Instead of ad hoc fetch requests from the $\mathrm{C}$-suite, they are more integrated on an on-going basis into actual operating units.

Here, both the high-value and low-value knowledge groups still skew heavily to top-down requests, but the high-knowledge industries have firms that are moving much more noticeably to $\mathrm{CI}$ independence with both wider use of analyst-initiated "Key Intelligence Topics" and reported embeddedness in decision-making. The differences aren't extreme, but they are noticeable and are possibly indicative of a more critical place in the organizational for the more mature firms in the high-value knowledge industries.

The items in the table then cover the nature of information used by intelligence operations. In terms of secondary research, the results are both expected and unexpected. The high-value knowledge group shows a wider disparity in practice, with some respondents reporting only web sources of information while others show a full range of integrated inputs, both inside and outside the core firm. The low-value knowledge group, on the other hand, shows no respondents at either extreme (just web or fully integrated). It's no surprise that the high-value group has more emphasis at the higher levels of secondary research, those results are as expected and appear significant. What is surprising is the higher percentage of firms using the presumably less sophisticated web-only approach.

There may be reasons for this, however. Mature CI operations may have more insights into what the critical data sources are in their industry. Base on their knowledge and experience, they likely already know the key secondary information resources to monitor on a regular basis and have already done their homework with potential internal and external sources of research. More experienced CI operations may also value primary research more highly than secondary, as the next group of results indicates. This question needs more research and may not apply widely (only a small percentage of the high-value knowledge group, fifteen percent, report this result) but it is certainly an interesting anomaly.

In the primary research area, the results are more predictable and more consistent. The high-value knowledge firms here have a clear emphasis on more developed practices, including an established human intelligence network, including both internal and external sources at the highest level. Over half the firms report these capabilities (52\%) while the percentage for low-value knowledge firms is only $18 \%$. Over $80 \%$ of these low-value knowledge 
firms report non-existent or untimely primary research inputs.

The analytical tools applied question also has some puzzling results. The high-value knowledge group shows almost $20 \%$ of firms reporting no analysis while the low-value knowledge group has none. The results between the groups at the presumably more mature analysis levels are then similar, though with somewhat higher percentages to the low-value group (reflecting the absence of responses in the lowest category). Once again, this result could use more study. But a possible explanation lies in the greater experience and knowledge in the high-value group. Because analysis of competitive data has been done previously, the reporting systems may include key indicators that have already established their value. The firm already knows these indicators meaning and contribution, so further analysis isn't necessary, just monitoring. But that is speculation, the topic needs more attention to fully address the unexpected results.

Finally, the table includes results concerning the perceived value of competitive intelligence in the organization, something of an overall measure of acceptance and support. These results are as expected. In the low-value knowledge group, the contributions of CI are either unrecognized or seen as necessary but perhaps beyond the current capabilities of the firm $(82 \%)$, thus having no formal role. The high-value knowledge group, on the other hand, shows close to half $(47 \%)$ of firms with some formal role for CI and/or a conviction by top management that its input is critical in decisionmaking.

All in all, the data provide evidence that the CI operations in the high-value knowledge group have been in place longer, generally with larger budgets, are more decentralized with more independence in their efforts, use more advanced primary research techniques, and is more valued by top managers in their organizations. The evidence on the sophistication of secondary research techniques is more mixed, as is that on analytical tools applied. Each of these may have explanations but definitely calls for more study.

\section{Conclusions}

This paper is a slice of a larger study that uses publicly reported financial data and a major competitive intelligence benchmarking study to assess the importance of knowledge to the originating firm (intellectual capital level) and to competitors (competitive intelligence activity level). Based on those more global results, we have identified two groups, those where knowledge is unambiguously important to both originator and competitors and those where it is unambiguously unimportant.

Industries and their respective firms from these groups were then mined for additional data on their competitive intelligence attitudes and activities. The results showed some clear distinctions, especially in the maturity and resource levels of competitive intelligence operations as well as in their role in the organization and their datagathering and analysis approaches. While evident and likely significant in most cases, the differences were not always huge and in a couple of examples (secondary research and analytical techniques) were not necessarily as expected.

So the results were interesting and, to a degree, confirm lend weight to the idea that different knowledge development and knowledge protection circumstances will lead to different operational practices by firms. In particular, high-value knowledge environments may be associated with greater maturity and effort in CI operations. We look forward to providing further insights on these matters.

Acknowledgement: The authors appreciatively acknowledge Fuld and Company for providing much of the key data used in this study.

\section{References}

Bernhardt, D. (1993), Perfectly legal competitor intelligence-How to get it, use it and profit from it, London: Pitman Publishing.

Bontis, N. (1999) Managing organizational knowledge by diagnosing intellectual capital: framing and advancing the state of the field. International Journal of Technology Management, 18 (5-8), 433-462.

Edvinsson, L. \& Sullivan, P. (1996) Developing a model for managing intellectual capital. European Management Journal, 14(4), 356364.

Erickson, G.S. \& Rothberg, H.N. (2012), Intelligence in Action: Strategically Managing Knowledge Assets, London: Palgrave Macmillan.

Fleisher, C.S. \& Bensoussan, B. (2002), Strategic and competitive analysis: Methods and techniques for analyzing business competition, Upper Saddle River, NJ: Prentice Hall.

Fuld, L.M. (1994), The new competitor intelligence: The complete resource for finding, analyzing, and using information about your competitors, New York: John Wiley \& Sons.

Gilad, B. (2003), Early warning: Using competitive intelligence to anticipate market shifts, control risk, and create powerful strategies, New York: AMACOM. 
Gilad, B. \& Herring, J., eds. (1996) The Art and Science of Business Intelligence. JAI Press: Greenwich, CT.

McGonagle, J. \& Vella, C. (2002), Bottom line competitive intelligence, Westport, CT: Quorum Books, Inc.

Prescott, J.E. \& Miller, S.H. (2001), Proven strategies in competitive intelligence: Lessons from the trenches, New York: John Wiley \& Sons.

Rothberg, H.N. \& Erickson, G.S. (2005) From Knowledge to Intelligence: Creating Competitive Advantage in the Next Economy. Elsevier Butterworth-Heinemann: Woburn, MA.

Rothberg, H.N. \& Erickson, G.S. (2002) Competitive capital: a fourth pillar of intellectual capital? in World Congress on Intellectual Capital Readings, Bontis, N. ed., Elsevier Butterworth-Heinemann: Woburn, MA.

Rouach, D., and Santi, P. (2001), Competitive intelligence adds value: Five intelligence attitudes, European Management Journal, 19:5, 552-559.

Sveiby, K-E. (2010) Methods for measuring intangible assets, www.sveiby.com/articles/IntangibleMethods.ht $\underline{\mathrm{m}}$.

Tan H.P., Plowman, D. \& Hancock, P. (2007). Intellectual capital and the financial returns of companies. Journal of Intellectual Capital, 8(1), 76-95.

Tobin, J. \& Brainard, W. (1977) Asset markets and the cost of capital, in R.R. Nelson \& B. Balassa, Economic Progress, Private Values, and Public Policy: Essays in Honor of William Fellner, Nelson, R. \& Balassa, B. eds., North Holland: Amsterdam.

Villalonga, B. (2004). Intangible resources, Tobin's $\mathrm{q}$, and sustainability of performance differences. Journal of Economic Behaviour and Organization, 54, 205-30.

Wright, S., Picton, D., \& Callow, J. (2002), Competitive intelligence in UK firms: A typology, Marketing Intelligence and Planning, 20:6, (October), 349-60. 